\title{
Ellipsis in tautologous conditionals: the contrast condition on ellipsis*
}

\author{
Richard Stockwell \\ University of California, Los Angeles
}

\begin{abstract}
I compare two theories to account for the novel observation that ellipsis is ungrammatical in tautologous conditionals: If John is wrong, then he is *(wrong). One theory attributes the ungrammaticality to a contrast failure in ellipsis parallelism (Rooth 1992a,b); the other to triviality at a more abstract, logical level (Gajewski 2009). The ellipsis parallelism theory prevails on further data, joining Griffiths (to appear) in arguing that contrast plays a role in ellipsis licensing. Contrast is further shown to be sensitive to intensionality.
\end{abstract}

Keywords: ellipsis, parallelism, contrast, triviality, tautology, conditionals

\section{Introduction}

We can say trivial things, like the tautologous conditional in (1a); but not the same sentence with ellipsis in (1b) (elided structure):

(1) a. If John is wrong, then he is wrong.

b. * If John is wrong, then he is wrong.

To my knowledge, the contrast in (1) is a novel observation: ellipsis is ungrammatical in tautologous conditionals.

I consider two competing accounts for this observation. On one, the problem is with the ellipsis, which fails to meet a semantic parallelism condition (Rooth 1992b). In particular, the two clauses are not in sufficient contrast (Rooth 1992a), as discussed in section 2. Alternatively, the problem is the tautology, which persists at a more abstract level to cause ungrammaticality. Concretely, we can extend Gajewski's (2009) theory of Logical-triviality to enforce ellipsis identity at the level of Logical Skeletons, as discussed in section 3. The two theories are compared against further

* This work began as part of my UCLA MA thesis: thanks to co-Chairs Yael Sharvit and Tim Stowell and committee members Nina Hyams and Dominique Sportiche. Further thanks to Dylan Bumford, Tim Hunter, Kyle Johnson, five anonymous SALT reviewers, and audiences at UCLA's SynSem, California Universities Semantics and Pragmatics 10 at UC Irvine, and SALT 28 at MIT. Section 3 fulfils the promissory note at the end of Stockwell 2017. All the errors are mine. 
Ellipsis in tautologous conditionals

data in section 4, where the ellipsis parallelism theory prevails. Section 5 considers role of contrast in more detail, showing that the contrast condition on ellipsis is sensitive to intensionality; implicated in other data patterns, including MaxElide effects (Griffiths to appear); and defuseable in utterances of agreement. Section 6 concludes.

\section{Ellipsis parallelism}

Rooth (1992b) argues that ellipsis is subject to the same semantic redundancy relation as focus (Rooth 1992a). After introducing Rooth's (1992a) theory of focus, I follow the spirit of Rooth (1992b) in applying it to ellipsis in tautologous conditionals. The crucial notion in Rooth's (1992a) theory for ruling out (1b) is contrast.

\subsection{Rooth's (1992a) theory of focus}

Rooth (1992a: 90, 93) proposes (2) as a constraint on focus interpretation: ${ }^{1}$

(2) Focus at the level of a phrase $\Phi$ requires an antecedent A such that either:

i. $\llbracket A \rrbracket \in \mathrm{F}(\Phi)$ and $\llbracket A \rrbracket \neq \llbracket \Phi \rrbracket$; or

ii. $\llbracket A \rrbracket \subseteq \mathrm{F}(\Phi)$

Clause (i) pertains to declarative antecedents. It requires first that the ordinary meaning of the antecedent $A$ be a member of the focus semantic value of the constituent containing focus $\Phi$ - the focus membership condition. Clause (i) additionally requires that $\mathrm{A}$ and $\Phi$ have distinct ordinary meanings — the contrast condition. By way of example, both of these conditions are met in (3). The proposition that John likes Mary is a member of the set of propositions of the form $x$ likes Mary, where $x$ ranges over individuals; so the focus membership condition is met. Further, the proposition that John likes Mary is distinct from the proposition that Bill likes Mary, satisfying the contrast condition: ${ }^{2}$

$$
\begin{aligned}
& \text { A: John likes Mary. } \quad \text { B: } \quad \text { BILL }_{F} \text { likes Mary, too. } \\
& \llbracket A \rrbracket=\text { likes }^{\prime}(m)(j) \quad \llbracket \Phi \rrbracket=\text { likes }^{\prime}(m)(b) \quad \mathrm{F}(\Phi)=\left\{\text { likes }^{\prime}(m)(x) \mid x \in D_{e}\right\} \\
& \llbracket A \rrbracket \in \mathrm{F}(\Phi) \text { and } \llbracket A \rrbracket \neq \llbracket \Phi \rrbracket
\end{aligned}
$$

Clause (ii) of the constraint in (2) pertains to question antecedents, whose ordinary meanings are sets of propositions (Hamblin 1973). It requires that the ordinary meaning of A be a subset of the focus semantic value of $\Phi$ - the subset

$1 \overline{F(E)}=$ focus semantic value of $E$, calculated by replacing $F$ (ocus)-marked constituents with variables of the same type.

2 Apostrophes indicate metalanguage expressions. The type of like' is $\langle e,\langle e,\langle s, t\rangle\rangle\rangle$. 
condition. The exchange in (4) meets this condition. The ordinary meaning of A and the focus value of $\Phi$ are both the set of propositions of the form $x$ likes Mary: ${ }^{3}$

$$
\begin{array}{ll}
\text { A: } \quad \text { Who likes Mary? } & \text { B: } \operatorname{JOHN}_{F} \text { likes Mary. } \\
\llbracket A \rrbracket=\left\{\text { likes }^{\prime}(m)(x) \mid x \in D_{e}\right\} & \llbracket \Phi \rrbracket=\text { likes }^{\prime}(m)(j) \\
\mathrm{F}(\Phi)=\left\{\text { likes }^{\prime}(m)(x) \mid x \in D_{e}\right\} & \llbracket A \rrbracket \subseteq \mathrm{F}(\Phi)
\end{array}
$$

The next subsection applies (2) to ellipsis.

\subsection{Rooth 1992b: applying Rooth 1992a to ellipsis}

Following the spirit of Rooth (1992b), ${ }^{4}$ ellipsis is subject to (5), which places exactly the same constraint on phrases E containing ellipsis as those $\Phi$ containing focus in (2). (5) is termed the parallelism condition on ellipsis licensing (cf. Fox 1999), since it requires a phrase containing ellipsis to have a 'parallel' antecedent:

(5) For $\varepsilon$ to be elided, $\varepsilon$ must be inside a phrase $E$ that has an antecedent A such that either:

$$
\begin{aligned}
& \text { i. } \llbracket A \rrbracket \in \mathrm{F}(\mathrm{E}) \text { and } \llbracket A \rrbracket \neq \llbracket E \rrbracket \text {; or } \\
& \text { ii. } \llbracket A \rrbracket \subseteq \mathrm{F}(\mathrm{E})
\end{aligned}
$$

(5) applies to the elliptical tautologous conditional from (1b) as in (6). The sentence is correctly predicted to be bad, since it fails the contrast condition: ${ }^{5}$

$$
\begin{array}{ll}
* \text { If } \mathrm{John}_{1} \text { is wrong, then he }{ }_{1} \text { is }_{F} \text { wrong. } & \varepsilon=\text { wrong } \\
\mathrm{E}=\mathrm{he}_{1} \text { is }_{F} \text { wrong } & \mathrm{A}=\mathrm{John}_{1} \text { is wrong } \\
\llbracket E \rrbracket=\text { wrong }^{\prime}(j) & \llbracket A \rrbracket=\text { wrong }^{\prime}(j) \\
\mathrm{F}(\mathrm{E})=\left\{\text { wrong }^{\prime}(j), \text { not }_{\text {-wrong }}(j)\right\} & \llbracket A \rrbracket \in \mathrm{F}(\mathrm{E}), \text { but } \llbracket A \rrbracket=\llbracket E \rrbracket
\end{array}
$$

In detail, ellipsis in (6) is subject to clause (i) of (5), since the antecedent John is wrong in the if-clause is declarative. The elided constituent $\varepsilon$ is the predicate wrong, which is contained in the clause $\mathrm{E}$ he $i s_{F}$ wrong. Focus on $i s_{F}$ introduces polar focus

3 Clause (ii) of (2) requires $\llbracket A \rrbracket \subseteq \mathrm{F}(\Phi)$ rather than $\llbracket A \rrbracket=\mathrm{F}(\Phi)$ in view of domain restrictions on questions, as for who to humans; i.e. for (4): $\left\{\operatorname{likes}^{\prime}(m)(x) \mid x \in D_{e} \& \operatorname{human}^{\prime}(x)\right\}$. $\llbracket A \rrbracket$ would then be a proper subset of - not equal to - $\mathrm{F}(\mathrm{E})$, which is calculated without restriction by definition.

4 See note 7 for the 'spirit of' caveat.

5 To the extent that ellipsis is just the extreme case of phonological deaccenting (Tancredi 1992), it is reassuring that the deaccenting in (i) is just as bad as the ellipsis in (1b):

(i) *If John is wrong, then he is wrong. 
Ellipsis in tautologous conditionals

alternatives for E: John is wrong, John is not wrong. ${ }^{6}$ The antecedent John is wrong is indeed a member of this set, so the focus membership condition is met. But the ordinary meanings of A and E are exactly the same. Thus (6) is ruled out as a failure of ellipsis licensing — in particular, the contrast condition.

It is worth emphasising that on the ellipsis parallelism theory $(1 \mathrm{~b})$ is ruled out solely by the contrast condition. Rooth (1992a) does not provide any data to motivate including the contrast condition in the constraint on focus interpretation in (2). Rather, Rooth (1992a: 90) is acting out of a methodological concern to constrain the theory as much as possible while retaining generality. With the elliptical tautologous conditional in (1b), however, we have a case where the contrast condition has empirical bite in ellipsis licensing in (5), as carried over from (2). ${ }^{7}$

In sum, the ellipsis parallelism theory rules out (1b) as in (6) for failing the contrast condition. The next section introduces an alternative theory, before the two are compared against further data in section 4.

6 F-marking is placed on $i s$ as the most natural way to try and pronounce (6). It means the focus membership condition is met, isolating the contrast failure as the reason for ungrammaticality. However, whatever F-marking is assigned in the apodosis of (6) - whichever head, branching node, or no F-marking at all - ellipsis will not be licensed, because contrast will fail regardless. The exception is F-marking on he, which makes (6) good, but does so by making the pronoun disjoint from John, changing the meaning of the sentence to be contingent and satisfying contrast. Contrastive focus on he referring to John is not supported when (1b) is uttered out of the blue. Any context that supports such contrastive focus will also supply an extra-sentential antecedent for the ellipsis that satisfies the contrast condition. See section 4.2 for more on extra-sentential antecedents.

7 While Rooth (1992b: ex. 2) argues that ellipsis is subject to the same semantic redundancy relation as focus from Rooth 1992a, Rooth (1992b: exx. 22, 23; 32) appears to jettison the contrast condition from (2) in suggesting that ellipsis in (i) can take the VP left as antecedent in (a) just as well as the whole sentence in (b). Both (a) and (b) meet the focus membership condition, but only taking the whole sentence as antecedent in (b) passes the contrast condition:

$$
\begin{aligned}
& \text { John left, and BILL } F \text { did teave, too. } \quad \varepsilon=\text { left } \\
& \text { a. } \mathrm{E}=\text { left } \quad \llbracket E \rrbracket=\text { leave }^{\prime} \quad \mathrm{F}(\mathrm{E})=\left\{\text { leave }^{\prime}\right\} \\
& \mathrm{A}=\text { left } \quad \llbracket A \rrbracket=\text { leave }^{\prime} \quad \llbracket A \rrbracket \in \mathrm{F}(\mathrm{E}) \text {, but } \llbracket A \rrbracket=\llbracket E \rrbracket \\
& \text { b. } \mathrm{E}=\mathrm{BILL}_{F} \text { left } \quad \llbracket E \rrbracket=\text { leave }^{\prime}(b) \quad \mathrm{F}(\mathrm{E})=\left\{\text { leave }^{\prime}(x) \mid x \in D_{e}\right\} \\
& \mathrm{A}=\text { John left } \quad \llbracket A \rrbracket=\text { leave }^{\prime}(j) \quad \llbracket A \rrbracket \in \mathrm{F}(\mathrm{E}) \text {, and } \llbracket A \rrbracket \neq \llbracket E \rrbracket
\end{aligned}
$$

For (a) to be a legitimate option, Rooth (1992b) must have cast aside the contrast condition. Subsequent research into the parallelism condition on ellipsis has followed Rooth (1992b) in omitting the contrast condition; for example, Fox 2000: 85, ex. 16; Takahashi \& Fox 2005. If the analysis of the ungrammaticality of (1b) in (6) as a contrast failure is on the right track, then the contrast condition should not be dropped from the theory of ellipsis parallelism. With the contrast condition, ellipsis parallelism has far greater empirical bite, requiring F-marking in $\mathrm{E}$, and disallowing degenerate singletons like $F(E)$ in (a). While its omission might seem innocent enough when extreme cases like (1b) are not at issue, it may have been derailing in others - see the discussion of so-called MaxElide effects (Griffiths to appear) in section 5.2. 


\section{L-triviality}

The previous section developed a theory which attributed the ungrammaticality of ellipsis in tautologous conditionals to a problem with ellipsis. This section considers an alternative theory that attributes the problem to tautology.

In aiming is to reconcile explanations of ungrammaticality in terms of tautology and contradiction with the fact that we can say trivial things, Gajewski $(2002,2009)$ hypothesises triviality to be ungrammatical only at a more abstract, logical level. His theory can be extended to account for the ungrammaticality of ellipsis in tautologous conditionals if we assume that ellipsis identity is enforced at this more abstract, logical level.

\subsection{Triviality and ungrammaticality}

Trivial truth conditions are regularly invoked to explain ungrammaticality (see Gajewski 2009; Abrusán 2014 for extensive references). For example, Barwise $\&$ Cooper (1981) explain the definiteness effect in there-existentials in terms of tautology. Weak determiners like some in (7a) are acceptable in quantificational there-associates, whereas strong determiners like every in (7b) are not:

a. There are some curious students.

b. * There is every curious student.

Supposing that there denotes the domain of individuals $D_{e}$, and that there-associates are predicates that apply to there, there-existential sentences with weak quantifiers are contingent, as in (8a); whereas there-existential sentences strong quantifiers are tautologous, as in (8b):

(8) a. (7a) is contingent on the existence of members of the set denoted by $P$ : $\llbracket$ some $\rrbracket(\llbracket P \rrbracket)(\llbracket$ there $\rrbracket)$ is true iff $\mathrm{P} \cap \mathrm{D}_{e} \neq \emptyset$

So when $\mathrm{P} \neq \emptyset, \llbracket(7 a) \rrbracket=$ True; but when $\mathrm{P}=\emptyset, \llbracket(7 a) \rrbracket=$ False

b. (7b) is a tautology, true regardless of the set denoted by $P$ :

$\llbracket$ every $\rrbracket(\llbracket P \rrbracket)(\llbracket$ there $\rrbracket)$ is true iff $\mathrm{P} \subseteq \mathrm{D}_{e}$

So for any $\mathrm{P}, \llbracket$ every $\rrbracket(\llbracket P \rrbracket)\left(\mathrm{D}_{e}\right)=$ True

Thus Barwise \& Cooper (1981) rule out strong determiners in there-existentials as tautologous. And yet, to Gajewski's (2009: ex. 27) great concern, we can say trivial things like in (9):

(9) a. It is raining and it isn't raining.

b. If Fred is wrong, then he is wrong.

c. Figure A is hexagonal or Figure A is not hexagonal. 
Ellipsis in tautologous conditionals

d. Every square is a square.

The grammaticality of tautologous and contradictory sentences undermines direct appeals to tautology and contradiction as an explanation for ungrammaticality. The next subsection outlines Gajewski's (2009) solution to this problem.

\subsection{Gajewski's (2009) theory of logical triviality}

Gajewski (2009) hypothesises that triviality is ungrammatical only at a more abstract, logical level. While the examples in (9) are perfectly acceptable, a formally identifiable subset of the trivial sentences are logically trivial, hence ungrammatical. Gajewski (2009: exx. 41, 42, 30) defines L(ogical)-triviality as in (10a) and relates it to ungrammaticality as in (10b). The definition of L-triviality refers to a sentence's logical skeleton (LS), defined in (10c). The intuition behind LSs is that the grammar treats all occurrences of non-logical constants as independent:

(10) a. A sentence S is L-trivial iff S's logical skeleton receives the truth-value 1 (or 0) in all interpretations.

b. A sentence is ungrammatical if its Logical Form contains a L-trivial constituent sentence.

c. To obtain the logical skeleton (LS) of an LF $\alpha$ :

i. Identify the maximal constituents of $\alpha$ containing no logical items;

ii. Replace each such constituent with a fresh constant of the same type.

Take for example, the conditional tautology in (11). In constructing the LS, while the logical item if is retained, the independent occurrences of the non-logical constant rain are replaced by independent arbitrary constants, $P$ and $Q$ :

(11) If it rains, it rains.

[ if $\mathrm{P} \quad \mathrm{Q}$ ]

The LS in (11) is not trivial. It is shared by other perfectly contingent sentences, e.g. If it rains, it pours. Therefore (11) is grammatical: although it is trivial, it is not L-trivial.

Compare the there-existential sentences from (7), which receive the LSs in (12). As detailed in (8), (12a) is contingent on the choice of $P$, whereas (12b) is true for any $P$. Since its LS in (12b) is trivial, (7b) is L-trivial, hence ungrammatical: ${ }^{8}$

(12) a. there are some $\mathrm{P}$

b. $X$ there is every $P$

The next subsection extends Gajewski's (2009) theory in (10) to ellipsis.

8 Reserving * for ungrammaticality, trivial LSs are marked $\boldsymbol{x}$. 
Stockwell

\subsection{Extending Gajewski 2009 to ellipsis}

Gajewski's theory of L-triviality reconciles the fact that we can say tautologous and contradictory things with explanations of ungrammaticality in terms of trivial truth conditions. We can extend Gajewski's theory to account the ungrammaticality of ellipsis in tautologous conditionals by adopting the additional assumptions in (13):

i. Ellipsis identity is checked at LS.

ii. Coreferential terms are replaced by the same variable at LS.

Assumption (i) requires the non-logical constants of an elided constituent to be identical at LS to the non-logical constants of its antecedent. Assumption (ii) resolves a point left open by Gajewski, but reduces to (i) on any theory that treats anaphora and ellipsis in the same way, e.g. Elbourne (2001), Hardt (1993).

Gajewski's theory of L-triviality in (10) extended by the assumptions in (13) applies to the elliptical tautologous conditional from (1b) as in (14). Since it has a trivial LS, (1b) is L-trivial, hence correctly predicted to be ungrammatical:

(14) * If $\mathrm{John}_{1}$ is wrong, then he $\mathrm{H}_{1}$ is wrong.

$$
x\left[\begin{array}{lll}
\text { if } \alpha & \text { is } \mathrm{P} \quad \text { then } \alpha \text { is } \mathrm{P} \quad \text { ] }
\end{array}\right.
$$

In detail, in building the LS for (14) the logical items if ... then and the copulas are retained. The non-logical items John and wrong in the protasis of the conditional, and he and wrong in the apodosis, are subject to replacement by arbitrary constants. However, by assumption (i) the elided wrong must be identical to its antecedent at LS; so both occurrences of wrong are replaced by the same constant $P$. Similarly, by assumption (ii) the coreferential terms John and he are dependent; so both are replaced by the same constant $\alpha$. The resulting LS is trivial. Hence the sentence is L-trivial, and ungrammatical.

Compare (15), which shows that the tautologous conditional without ellipsis from (1a) is not L-trivial. With no ellipsis, no identity is enforced between the two occurrences of wrong, and each is replaced by an independent arbitrary constant. As in (11) above, the resulting LS is contingent. Therefore (15) is correctly predicted to be grammatical - trivial but not L-trivial:

$$
\begin{aligned}
& \text { If } \mathrm{John}_{1} \text { is wrong, then he }{ }_{1} \text { is wrong. } \\
& \text { [ [ } \begin{array}{ll}
\text { if } \alpha \text { is } \mathrm{P} \text { then } \alpha \text { is } \mathrm{Q}
\end{array}
\end{aligned}
$$

In sum, extending Gajewski's (2009) theory to enforce ellipsis identity over LSs rules out (1b) as L-trivial. The next section introduces further data to adjudicate between this extended theory of L-triviality and the competing ellipsis parallelism theory from section 2 . 
Ellipsis in tautologous conditionals

\section{Further data}

The two theories developed in the previous sections are equally capable of accounting for the ungrammaticality of ellipsis in tautologous conditionals. On the first, ellipsis in (1b) fails the contrast condition of parallelism. On the second, ellipsis identity at the level of logical skeletons renders (1b) logically trivial, hence ungrammatical.

(1) a. John is wrong, then he is wrong.

b. * If John is wrong, then he is wrong.

This section shows that the ellipsis parallelism theory fares better with respect to further, related data. Having concluded as much, section 5 will examine ellipsis parallelism in more detail, considering a refinement, extensions, and a problem for the theory.

\subsection{Other trivial sentences}

Both theories successfully extend to the tautologies in (16) and (17). As with the tautologous conditional from (1), the (a) examples are trivial but perfectly grammatical, whereas the (b) examples with ellipsis are ungrammatical. According to ellipsis parallelism, there is no available properly contrasting antecedent to license ellipsis. Meanwhile according to extended L-triviality, the elliptical (b) examples are L-trivial, having the trivial LSs * [every $P$ is a $P]$ and $*[P$ will be $P]$ respectively:

(16) a. Every square is square.

b. * Every square is square.

a. Boys will be boys.

b. * Boys will be boys.

However, the predictions of the two theories diverge for ellipsis in other trivial sentences for example, the tautologous disjunction in (18) and the contradictory conjunction in (19):

(18) Either John ${ }_{1}$ is wrong, or he ${ }_{1}$ isn't wrong.

(19) John ${ }_{1}$ is wrong and he ${ }_{1}$ isn't wrong.

Ellipsis parallelism correctly predicts both (18) and (19) to be grammatical as in (20), where the opposition of a positive antecedent and a negative clause containing ellipsis satisfies the contrast condition:

$$
\begin{array}{ll}
\mathrm{E}=\text { he }_{1} \text { isn't }_{F} \text { wrong } & \mathrm{A}=\mathrm{John}_{1} \text { is wrong } \\
\left.\llbracket E \rrbracket={\text { not }- \text { wrong }^{\prime}(j)}^{\mathrm{F}(\mathrm{E})=\left\{\text { wrong }^{\prime}(j),\right. \text { not-wrong }}(j)\right\} & \llbracket A \rrbracket=\text { wrong }^{\prime}(j) \\
\llbracket A \rrbracket \in \mathrm{F}(\mathrm{E}), \llbracket A \rrbracket \neq \llbracket E \rrbracket
\end{array}
$$


In detail, the ellipses in (18) and (19) are subject to clause (i) of (5), since the antecedent John is wrong in the first conjunct is declarative. The elided constituent wrong is contained in the clause $\mathrm{E}$ he is not wrong. Focus on not introduces polar focus alternatives for E: John is wrong, John is not wrong. The antecedent John is wrong is indeed a member of this set, so the focus membership condition is satisfied, similar to (1b) in (6). But, unlike with (1b), the ordinary meanings of A and E are distinct: A is positive, whereas E contains sentential negation. So the contrast condition is satisfied, and (18) and (19) are correctly predicted to be grammatical.

The extended L-triviality theory, on the other hand, incorrectly predicts ellipsis to be ungrammatical in all trivialities. (18) and (19) are assigned the trivial LSs [ $\alpha$ is $P$ or/and $\alpha$ is not $P$ ], predicting them to be L-trivial and ungrammatical.

One way for extended L-triviality to remedy this bad prediction would be to claim that (18) and (19) are not really trivialities. For example, Alxatib, Pagin \& Sauerland (2013) treat borderline contradictions like John is and isn't tall using fuzzy logic to allow for each conjunct to be half true, hence the whole sentence to be true. If (18) and (19) were rendered non-trivial in this way, then they would not be L-trivial, and ellipsis would be predicted to be fine. That said, this treatment of apparent trivialities as non-trivial would have to be prevented from extending to (1) for the theory to make the right cut regarding ellipsis between (1b) on the one hand and (18) and (19) on the other.

In sum, ellipsis parallelism handles the status of ellipsis in other trivialities very naturally; whereas in order to prevent incorrect predictions about the status of ellipsis in tautologous disjunctions and contradictory conjunctions, extended L-triviality has to appeal to theories which render them non-trivial.

\subsection{Extra-sentential antecedents}

Both theories correctly predict the exchange in (21) to be good, despite speaker B's response in (21) being the same as (1b):
A: Is John 1 wrong?
B: If $\mathrm{John}_{1}$ is wrong, then he ${ }_{1}$ is wrong.

On both theories, the problem with ellipsis inside the tautologous conditional is circumvented by sourcing the antecedent from the polar question in A rather than the if-clause in B. We can be sure that the antecedent is the question in (21) based on the minimally different exchange in (22). The only possible interpretation for the ellipsis site in B is silly, sourced from the question in A; a tautologous interpretation with wrong sourced from the if-clause is not available:
A: Is Fred 2 silly?
B: If Fred ${ }_{2}$ is wrong, then he 2 is silly / *wrong.

Ellipsis parallelism treats (21) as in (23), where the question antecedent invokes clause (i) of the parallelism condition from (5), circumventing the contrast condition: 
Ellipsis in tautologous conditionals

$$
\begin{aligned}
& \mathrm{E}=\mathrm{he}_{1} \text { is }_{F} \text { wrong } \\
& \llbracket E \rrbracket=\text { wrong }^{\prime}(j) \\
& \mathrm{F}(\mathrm{E})=\left\{\text { wrong }^{\prime}(j), \text { not }- \text { wrong }^{\prime}(j)\right\} \quad \llbracket A \rrbracket \subseteq \mathrm{F}(\mathrm{E})
\end{aligned}
$$

In detail, $\mathrm{E}$ and its focus value are unchanged from the treatment of the tautologous conditional. The ellipsis cannot take the if-clause as its antecedent, since this would result in a contrast failure, as for (1b) in (6). Instead, the ellipsis sources its antecedent from the polar question. With a question as the antecedent, the ellipsis is subject to clause (ii) of (5) - the subset condition. Following Hamblin (1973), the polar question denotes the set of its possible answers: John is wrong, John is not wrong. This set is the same as the focus value of $\mathrm{E}$. So the subset condition is met and ellipsis is licensed without the contrast problem arising.

Extended L-triviality theory also predicts the exchange in (21) to be good as in (24), where sourcing the antecedent for ellipsis from outside the sentence circumvents L-triviality:
A: Is John 1 wrong? [ [ [ $\left.\begin{array}{ll}\text { is } \alpha & \mathrm{P}\end{array}\right]$
B: If $\mathrm{John}_{1}$ is wrong, then he 1 is wrong.
[ if $\alpha$ is Q then $\alpha$ is $\mathrm{P}$

In detail, extended L-triviality enforces ellipsis identity at the level of logical skeletons. To meet this restriction, the ellipsis in B and its antecedent in A are replaced with the same constant $P$ in the LSs in (24). The occurrence of wrong in the if-clause is not involved in the ellipsis relationship, so is replaced with the independent $Q$. The LS for B is then not trivial, but shared by perfectly contingent sentences, e.g. If John is lucky, then he is happy. Thus (24) is not L-trivial, but grammatical.

In sum, both theories correctly predict that tautologous conditionals can contain ellipsis when the antecedent comes from a polar question, which circumvents the problem with sourcing the antecedent from the if-clause - failure to contrast and L-triviality, respectively.

Beyond the matrix polar question in (21), both theories continue to make correct predictions when the extra-sentential antecedent is an embedded polar question, which is good in (25), or a wh-question, which is bad in (26):

(25) A: I wonder whether John 1 is wrong.

$\mathrm{B}$ : If $\mathrm{John}_{1}$ is wrong, then he 1 is wrong.
A: What is $\mathrm{John}_{1}$ (like)?
B: *If $\mathrm{John}_{1}$ is wrong, then he $\mathrm{H}_{1}$ is wrong.

Assuming that embedded polar questions, like matrix questions, denote the set of possible answers (Karttunen 1977), ellipsis parallelism treats (25) in exactly the same way as (21) in (23). In (26), on the other hand, the subset condition is not met. The antecedent $w h$-question denotes the set of propositions where a property is applied to John, i.e. $\left\{P(j) \mid P \in D_{\langle e, s t\rangle}\right\}$, which is clearly not a subset of

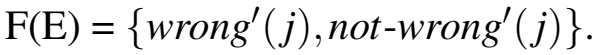


Extended L-triviality also makes the right cut between (25) and (26). In order to circumvent L-triviality, ellipsis identity needs to be established with an occurrence of wrong outside the tautologous conditional. A provides such an extra-sentential occurrence of wrong in (25), but not (26).

However, predictions diverge when the extra-sentential antecedent for ellipsis in a tautologous conditional is a declarative, as in (27):

A: John 1 is wrong. $\quad$ B: ? If John 1 is wrong, then he ${ }_{1}$ is wrong.

Ellipsis parallelism predicts the exchange in (27) to be bad. With a declarative antecedent, a contrast failure is predicted to arise just as for (1b) in (6), regardless of whether the antecedent is sourced from inside or outside the tautologous conditional. For extended L-triviality, on the other hand, the extra-sentential occurrence of wrong provided by A should be enough to circumvent L-triviality, predicting the exchange in (27) to be good. The empirical status of the exchange in (27) is unclear.

In sum, pending further discussion of cases like (27) in section 5.3 below, both theories make good predictions regarding extra-sentential antecedents for ellipsis in tautologous conditionals, where the problem with sourcing the antecedent from the if-clause can be circumvented by sourcing it from outside the sentence instead. But while extended L-triviality already had to make complicating assumptions to handle the status of ellipsis in some other trivialities in section 4.1, it comes thoroughly unstuck on double ellipsis, as discussed in the next subsection.

\subsection{Double ellipsis}

Ellipsis parallelism and extended L-triviality really come apart in relation to the sentence in (28) with ellipsis in both clauses of the conditional at once:

(28) If he is $_{1}<>$ he $_{1}$ is $<>$.

Though it need not, (28) can have a trivial interpretation where both ellipses are resolved via the same antecedent, as in the exchange in (29):
A: Is John 1 wrong?
B: If he ${ }_{1}$ is wrong, he ${ }_{1}$ is wrong.

Ellipsis parallelism correctly predicts the exchange in (29) to be good. Each ellipsis in B is separately and successfully licensed by the subset condition in just the same way as the ellipsis in (21) was in (23) in the previous subsection.

Extended L-triviality, on the other hand, incorrectly predicts the exchange in (29) to be bad, as in (30):
A: Is $\mathrm{John}_{1}$ wrong? [ [ $\left.\begin{array}{ll}\text { is } \alpha & \mathrm{P}\end{array}\right]$
B: If $\mathrm{John}_{1}$ is wrong, then he $\mathrm{H}_{1}$ is wrong. $\boldsymbol{X}$ [ [ if $\alpha$ is $\mathrm{P}$ then $\alpha$ is $\mathrm{P}$ 
Ellipsis in tautologous conditionals

Both ellipses are dependent on the same antecedent, so both will be replaced by the same arbitrary constant at LS, here $P$. This results in a trivial LS, rendering B L-trivial and incorrectly predicting it to be ungrammatical.

Extended L-triviality's prediction for (29) seems to be hopelessly incorrect. Thus the ellipsis parallelism theory prevails. ${ }^{9}$

\subsection{Interim conclusion: ellipsis parallelism}

This section compared ellipsis parallelism and extended L-triviality, two theories that were equally able to account for the ungrammaticality of ellipsis in tautologous conditionals in sections 2 and 3. Whereas ellipsis parallelism extends naturally to ellipsis in other trivial sentences, extended L-triviality has to make additional, complicating assumptions about the meaning of disjunction and conjunction. Both analyses correctly predict that ellipsis in a tautologous conditional becomes good when the antecedent is sourced from (a polar question) outside the sentence, circumventing the respective contrast and L-triviality problems with sentence-internal ellipsis licensing. But only ellipsis parallelism correctly rules in cases where two ellipses are resolved via the same sentence-external antecedent. ${ }^{10}$

9 However, there is more to say about the status of double ellipsis in (28) as opposed to single ellipsis in (1b). While (28) needs to be provided with an antecedent before it can be interpreted, as in (29), it can also be judged acceptable in isolation. The acceptability of (28) out of the blue suggests a willingness to assume that a discourse could readily be provided to resolve the ellipses. But we do not seem to be willing to make the same allowances for (1b). (1b) is judged unacceptable in isolation, despite that fact that there are discourses where it is good - as the previous subsection showed with (21). It seems that the presence of a potential but unlicensed antecedent in the if-clause in (1b) precludes the deference to discourse tolerated in (28) when no potential antecedent is available.

The data in (i) replicate this pattern with focus:
a. Bill is AMERICAN A $_{\text {. }}$
b. John is Canadian. Bill is AMERICAN $_{F}$.
c. ?? John is American. Bill is AMERICAN $_{F}$.

(a) behaves like double ellipsis in (28): there is no discourse to resolve the antecedent of the focus/ellipsis, but we are willing to assume that one could readily be provided, and judge the sentence acceptable. (b) is like single ellipsis in the exchange in (21): the first sentence provides a legitimate antecedent for the focus/ellipsis in the second. Finally, (c) is like (1b): there is a potential but unlicensed, non-contrasting antecedent for the focus/ellipsis, and the sentence is judged unacceptable. Why potential but unlicensed antecedents should derail deference to discourse to the point of unacceptability will have to remain a question for future research. Still, the similar pattern observed for focus and ellipsis in this regard provides support for the ellipsis parallelism theory's application of the condition on focus interpretation (Rooth 1992a) to ellipsis (Rooth 1992b).

10 In addition to its failure on double ellipsis case in (28), there are other reasons to be suspicious of extended L-triviality as a theory for the ungrammaticality of ellipsis in tautologous conditionals. First, the status of (1b) is awkward rather than atrocious, and becomes acceptable with an extra- 
Having concluded in its favour, the next section examines the ellipsis parallelism theory — and in particular the contrast condition — in more detail.

\section{More on contrast in ellipsis}

The ellipsis parallelism theory accounts for the ungrammaticality of ellipsis in tautologous conditionals as a contrast failure. This subsection subjects the contrast condition to greater scrutiny. First, a refinement, showing that contrast is sensitive to intensionality. Second, some extensions, showing that contrast accounts for other ungrammatical ellipsis, including so-called MaxElide effects (Griffiths to appear). Third, a problem, in that the contrast condition seems not to apply in elliptical utterances of agreement.

\subsection{Contrast and intensionality in tautologous free relatives}

Beyond the titular concern of this paper with ellipsis in tautologous conditionals, the data in (31) introduce another contrast in the status of ellipsis in tautologies, this time in tautologous free relatives (cf. Horn 1981: 326):

(31) a. John eats what he eats.

b. * John eats what he does eat.

c. Mary believes that John eats what he does eat.

Just as with conditional tautologies, (31a) without ellipsis is trivial but perfectly grammatical, whereas (31b) with ellipsis is ungrammatical. Regardless of how the free relative DP takes scope to resolve antecedent containment, ${ }^{11}$ and regardless of the placement of F-marking, ellipsis is ruled out in (31b) as a contrast failure as in (32), since A and $\mathrm{E}$ have the same meaning:

$$
\begin{aligned}
& {\left[D P \text { what }_{k} \text { he }_{1} \text { does eat } t_{k}\right]_{i} \mathrm{John}_{1} \text { eats } t_{i} .} \\
& \mathrm{A}=\mathrm{John}_{1} \text { eats } t_{i} \quad \mathrm{E}=\mathrm{he}_{1} \text { does eat } t_{k} \quad \llbracket A \rrbracket=\llbracket E \rrbracket
\end{aligned}
$$

sentential antecedent in (21); whereas motivating data for L-triviality, like the definiteness effect in there-existentials in (7b), are grotesquely and irredeemably ungrammatical. Second, it is unclear how ellipsis and logical skeletons would interact. The crucial assumption in extending L-triviality to account for the ungrammaticality of ellipsis in tautologous conditionals was for ellipsis identity to hold at the level of logical skeletons. But why should LSs 'see' ellipsis? If ellipsis is PF-deletion (Ross 1967), it would not be visible at LF, let alone the more abstract level of LS. And even if ellipsis is mediated at LF (Chung, Ladusaw \& McCloskey 1995), ellipsis sites will have been filled in by LS, meaning what started out as ellipsis and what did not would no longer be recoverable.

11 To avoid antecedent containment, A needs to exclude the elliptical free relative DP. For parallelism with A, E needs to exclude what. And to avoid syntactic overlap between A and E (Rooth 1992a), the free relative DP needs to move over John. 
Ellipsis in tautologous conditionals

However, embedded under the intensional predicate believe makes ellipsis grammatical in (31c). On our ellipsis parallelism theory so far, (31c) would receive the same treatment as (31b), namely (32), on which it is predicted to be ungrammatical. But whereas intensional predicates usually introduce de re-de dicto ambiguities, the free relative DP in (31c) can only be read de re. The sentence asserts that Mary is correct, equating what John actually eats with what Mary believes him to eat. The free relative DP cannot be read de dicto, whereby the sentence would assert that Mary believes the tautology that what John eats is what he eats.

The availability of a de re but not a de dicto reading of (31c) can be explained if the contrast condition in ellipsis parallelism is sensitive to intensionality, as in (33). The syntactic structure in (33a) has the LF in (33b). The structure and meaning of the antecedent $\mathrm{A}$ are as in $(33 \mathrm{c})$. The de dicto reading is not available, because it fails the contrast condition, as in (33d) parallel to (32). But on the de re treatment in (33e), the contrast condition is satisfied by the opposition of what John eats in Mary's belief worlds with what he eats in the actual world. Meanwhile, prosodic focus on DOES realises focal alternatives to worlds, satisfying the focus membership condition in (33f):

a. Mary believes that John eats what $k$ he $\operatorname{DOES}_{F}$ eat $t_{k}$.

b. Mary believes 7 that [what 4 [he ${ }_{1}$ eats $\left.\left.\mathrm{t}_{4}\right] \mathrm{w}_{0 F} /{ }^{*} \mathrm{w}_{7 F}\right] 3\left[\mathrm{John}_{1}\right.$ eats $\left.\mathrm{t}_{3}\right] \mathrm{w}_{7}$
c. $A=3\left[J_{o h n}\right.$ eats $\left.t_{3}\right] w_{7}$
d. $\mathrm{E}_{\text {de dicto }}=4\left[\right.$ he $_{1}$ eats $\left.\mathrm{t}_{4}\right] \mathrm{w}_{7 F}$
$\llbracket E_{\text {de dicto }} \rrbracket=\lambda x$.eats $s^{\prime}(x)(j)\left(w_{7}\right) \quad \llbracket A \rrbracket=\llbracket E_{\text {de dicto }} \rrbracket$
e. $\mathrm{E}_{d e ~ r e}=4\left[\mathrm{he}_{1}\right.$ eats $\left.\mathrm{t}_{4}\right] \mathrm{w}_{0 F}$
$\llbracket E_{\text {de re }} \rrbracket=\lambda x \cdot e a t s^{\prime}(x)(j)(@)$
$\llbracket A \rrbracket \neq \llbracket E_{\text {de re }} \rrbracket$
f. $\mathrm{F}\left(\mathrm{E}_{\text {de re }}\right)=\left\{\lambda x . e a t s^{\prime}(x)(j)(w) \mid w \in W\right\}$
$\llbracket A \rrbracket \in \mathrm{F}\left(\mathrm{E}_{\text {de re }}\right)$

$\llbracket A \rrbracket=\lambda x . e \operatorname{eats}^{\prime}(x)(j)\left(w_{7}\right)$

Further to embedding under an intensional verb like believe in (31c), ellipsis is grammatical in the tautologous free relatives in (34) under an intensional noun like fact (Moulton 2009) in (34a) and with the intensional operator because (Kratzer 1998) in (34b) (again, cf. Horn 1981): ${ }^{12}$

12 The paradigm in (31) recalls Russell's (1905) ambiguity (the main topic of Horn 1981) in (i). Whereas (a) is at best infelicitous, it is perfectly acceptable when embedded under an intensional verb like believe in (b):

(i) a. ?? Mary is as tall as she is.

b. Mary believes she's taller than she is.

On a de re reading of (b), Mary is mistaken - she is shorter than she thinks she is. On a de dicto reading, Mary subscribes to an arrant contradiction — that her height exceeds itself. Ellipsis 
(34) a. The fact that John eats what he does eat is disappointing.

b. John eats what he does eat because he's training for a marathon.

In sum, the contrast condition on ellipsis parallelism is sensitive to intensionality: contrast is satisfied when the antecedent and the clause containing are ellipsis are interpreted relative to different (sets of) worlds. The next subsection surveys additional cases where failure to contrast explains the ungrammaticality of ellipsis.

\subsection{Further contrast failures}

The contrast condition, incorporated from Rooth's (1992a) theory of focus following the spirit of Rooth (1992b), was central to accounting for the ungrammaticality of ellipsis in tautologous conditionals in section 2. This subsection extends the empirical bite of the contrast condition to three other cases of ellipsis it renders ungrammatical: iteration, conjunction, and so-called MaxElide effects (Griffiths to appear).

First, ellipsis is impossible in sentences expressing iteration, as in (35). The repetition must be whole, whether of sentences (35a) or verb phrases (35b). Ellipsis in the corresponding (35b) and (35d) is ruled out by the contrast condition - there is no available antecedent with a distinct meaning from the clause containing ellipsis:
a. They talked and they talked and they talked.
b. * They talked and they did talk and they did talk.
c. They talked and talked and talked.
d. * They talked and did talk and did talk.

Second, the conjunction of a sentence with itself, as in (36a), is affrontingly trivial, but nevertheless grammatical. Ellipsis, however, is impossible in (36b), due to contrast failure. Interestingly, the ungrammaticality extends to the nominal coordination in (36c), perhaps lending support to a sentence conjunct reduction analysis of nominal conjunction (see Hirsch 2017 for references):
a. Every student left and every student left.
b. * Every student left and every student did leave.
c. * Every student and every student left.

parallelism with an intensionally sensitive contrast condition predicts the contradictory de dicto reading to be ungrammatical in (b) just as in (31c), for the reason in (33); yet it is reported to be available. The obligatoriness of comparative ellipsis could be complicating matters here, however. 
Ellipsis in tautologous conditionals

Third, Griffiths (to appear) argues that the contrast condition in ellipsis parallelism is responsible for so-called MaxElide effects, exemplified in (37). From a base sentence like (37a), sluicing is possible in (37b), but verb phrase ellipsis is not in $(37 \mathrm{c})$ :
a. John will kiss someone, but I don't know who he will kiss $t$.
b. John will kiss someone, but I don't know who he will kiss $t$.
c. * John will kiss someone, but I don't know who he will kiss $t$.

Using the theory of ellipsis parallelism in (5), Griffiths shows that ellipsis is not licensed in (37c) because the clause containing ellipsis does not contrast with its antecedent, as in (38). When there is contrast, however, as between John and Mary in (39), ellipsis is successfully licensed: ${ }^{13}$

$$
\begin{array}{ll}
\mathrm{E}=6 \text { he }_{1} \text { will kiss } t_{6} & \mathrm{~A}=8 \mathrm{John}_{1} \text { will kiss } t_{8} \\
\llbracket E \rrbracket=\lambda x . \text { kiss }^{\prime}(x)(j) & \llbracket A \rrbracket=\lambda y . k i s s^{\prime}(y)(j) \\
\mathrm{F}(\mathrm{E})=\left\{\lambda x . \text { kiss }^{\prime}(x)(j)\right\} & \llbracket A \rrbracket \in \mathrm{F}(\mathrm{E}), \text { but } \llbracket A \rrbracket=\llbracket E \rrbracket
\end{array}
$$

(39) I know who $\mathrm{JOHN}_{F}$ will kiss $t_{5}$ and whog MARY $\mathrm{M}_{F}$ will kiss $t_{9}$.

$$
\mathrm{E}=9 \mathrm{MARY}_{F} \text { will kiss } t_{9} \quad \mathrm{~A}=5 \mathrm{JOHN}_{F} \text { will kiss } t_{5}
$$

$$
\begin{array}{ll}
\llbracket E \rrbracket=\lambda x \cdot k i s s^{\prime}(x)(m) & \llbracket A \rrbracket=\lambda y \cdot k i s s^{\prime}(y)(j) \\
\mathrm{F}(\mathrm{E})=\left\{\lambda x \cdot k i s s^{\prime}(x)(z) \mid z \in D_{e}\right\} & \llbracket A \rrbracket \in \mathrm{F}(\mathrm{E}) \text { and } \llbracket A \rrbracket \neq \llbracket E \rrbracket
\end{array}
$$

Previous accounts of (37) have been phrased in terms of ellipsis parallelism, but omit the contrast condition from (5) (e.g. Takahashi \& Fox 2005). Without the contrast condition, (37c) is incorrectly predicted to be grammatical, since it passes the focus membership condition. These accounts accept that ellipsis licensing is successful in (37c), attributing its ungrammaticality instead to the workings of MaxElide (40) (Merchant 2008).

(40) MaxElide: maximal elision must occur in parallelism domains.

On this view, ellipsis is successfully licensed in both (37b) and (37c) with respect to the same A and E; but since there is more ellipsis in (37b), (37c) is ungrammatical by $(40)$.

Griffiths (to appear) rightly criticises MaxElide as an ad hoc solution to (37): transderivational comparison ranges over very conveniently chosen competitors, conspicuously omitting the perfectly good option of eliding nothing at all in (37a). Treating (37c) as a contrast failure improves conceptually on this situation by ruling

13 Sluicing (37b), on the other hand, is subject to a separate Question-Under-Discussion based licensing condition requiring semantic identity between questions (Barros 2014), where (5) has no purview. 
it out on its own terms, rather than as the loser of a competition with (37b). ${ }^{14}$ Thus the current paper on ellipsis in tautologous conditionals and Griffiths (to appear) on so-called MaxElide effects converge on attributing a crucial role to the contrast condition of Rooth (1992a) in theories of ellipsis parallelism. ${ }^{15}$

\subsection{Defusing contrast}

The perfectly good exchange in (41) presents a problem for incorporating Rooth's (1992a) contrast condition in the theory of ellipsis parallelism, since $\llbracket A \rrbracket=\llbracket E \rrbracket:{ }^{16}$

\section{(41) A: John is wrong. $\mathrm{B}: \quad$ Yes, he $\mathrm{IS}_{F}$ wrong.}

Since it was already argued in section 5.1 that the contrast condition is sensitive to intensionality, we could attempt to attribute the goodness of (41) to the fact that the clause containing ellipsis and its antecedent are uttered with respect to the different epistemic states of each speaker. But that would not sit well with the ellipsis parallelism theory's conflation of focus licensing and ellipsis licensing given the badness of (42), where contrastive focus across speakers is no good:

14 Griffiths (to appear) also points out a number of empirical inadequacies with the MaxElide analysis. But his analysis is complicated by his position on the incompatibility of alternative semantics and A' $\lambda$-binding in (i):

(i) $\lambda$-intervention: phrases containing an A' $\lambda$-binder have no focus semantic value (Kotek 2016).

Assuming (i) requires the further assumptions in (ii)-(v) to keep the analysis on track:

(ii) $\exists$-closure: when calculating ellipsis licensing, existentially-bind free variables in A and E.

(iii) Trace conversion: tails of A'-chains are interpreted as definite descriptions at LF (Fox 2002).

(iv) Focused traces: the converted trace of a focused element can bear focus.

(v) E-type replacement: E-type pronouns (Evans 1980) can replace A' $\lambda$-binding.

Taken together, these assumptions lead to the prediction that sloppy readings should be unavailable when the (trace of) contrastive focus that is satisfying the contrast condition c-commands the $\lambda$-binder that would create sloppiness. However, a sloppy reading is available in a configuration of this kind in (vi):

(vi) $\mathrm{JOHN}_{F}$ thinks that if every $\operatorname{girl}_{k}$ loved her ${ }_{k}$ mother, it would be great.

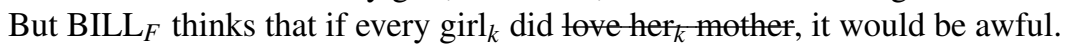

In (vi), elided her can be bound by every girl, which must scope lower than the contrastively focused subject since it is trapped in an if-clause scope island.

15 Griffiths (to appear) attributes the version of ellipsis parallelism in (5) that includes the contrast condition to Rooth (1992b). But recall the discussion in note 7.

16 Recall the inconclusive discussion of the declarative extra-sentential antecedent in (27) in section 4.2. 
Ellipsis in tautologous conditionals

$$
\begin{aligned}
& \text { A: John likes Mary. } \quad \text { B: } \quad * \text { Yes, } \mathrm{JOHN}_{F} \text { likes Mary. } \\
& \llbracket A \rrbracket=\text { likes }^{\prime}(m)(j) \quad \llbracket \Phi \rrbracket=\text { likes }^{\prime}(m)(j) \quad \mathrm{F}(\Phi)=\left\{\text { likes }^{\prime}(m)(x) \mid x \in D_{e}\right\} \\
& \llbracket A \rrbracket \in \mathrm{F}(\Phi) \text { but } \llbracket A \rrbracket=\llbracket \Phi \rrbracket
\end{aligned}
$$

However, the problem with (41) only stands if we subject it to clause (i) of the ellipsis parallelism from (5), with speaker A providing a declarative antecedent. Alternatively, we could view speaker A as proffering alternatives, establishing a Question-Under-Discussion (Roberts 1996) as to whether John is wrong. Taking this QUD as antecedent moves us to clause (ii) of the parallelism condition, allowing speaker B's response to circumvent the contrast condition.

\section{Conclusion}

This paper analysed the novel observation that ellipsis is ungrammatical in tautologous conditionals as a failure of ellipsis licensing. In particular, ellipsis in such sentences fails Rooth's (1992a) contrast condition, which is a crucial part of the theory of ellipsis parallelism (see also Griffiths to appear). Extended L-triviality was considered as a rival theory, but ellipsis parallelism proved superior. The contrast condition was also shown to be sensitive to intensionality and to have empirical bite beyond tautologous conditionals.

\section{References}

Abrusán, Márta. 2014. Weak Island Semantics. Oxford: Oxford University Press.

Alxatib, Sam, Peter Pagin \& Uli Sauerland. 2013. Acceptable contradictions: pragmatics or semantics? A reply to Cobreros et al. Journal of Philosophical Logic 42. 619-634. doi:10.1007/s10992-012-9241-7.

Barros, Matthew. 2014. Sluicing and identity in ellipsis. New Brunswick, New Jersey: Rutgers University dissertation. doi:10.7282/T3VM49R5.

Barwise, Jon \& Robin Cooper. 1981. Generalized quantifiers and natural language. Linguistics and Philosophy 4. 159-219. http://www.jstor.org/stable/25001052.

Chung, Sandra, William Ladusaw \& James McCloskey. 1995. Sluicing and logical form. Natural Language Semantics 3(3). 239-282. doi:10.1007/BF01248819.

Elbourne, Paul. 2001. E-type anaphora as NP-deletion. Natural Language Semantics 9. 241-288. doi:10.1023/A:1014290323028.

Evans, Gareth. 1980. Pronouns. Linguistic Inquiry 11. 337-362. http://www.jstor.org/stable/4178164.

Fox, Danny. 1999. Focus, parallelism and accommodation. In Proceedings of SALT IX, 70-90. Ithaca, NY: CLC Publications.

Fox, Danny. 2000. Economy and Semantic Interpretation. Cambridge, MA: MIT press. 
Fox, Danny. 2002. Antecedent-contained deletion and the copy theory of movement. Linguistic Inquiry 33. 63-96. doi:10.1162/002438902317382189.

Gajewski, Jon. 2002. L-analyticity and natural language. Ms., MIT.

Gajewski, Jon. 2009. L-triviality and grammar. Handout of a talk at University of Connecticut Logic Group, 27th February.

Griffiths, James. to appear. Beyond MaxElide: An investigation of A'-movement from elided phrases. Linguistic Inquiry. doi:10.1162/ling_a_00317.

Hamblin, Charles L. 1973. Questions in Montague English. Foundations of Language 10. 41-53.

Hardt, Daniel. 1993. Verb phrase ellipsis: Form, meaning, and processing. Philadelphia, Pennsylvania: University of Pennsylvania dissertation.

Hirsch, Aron. 2017. An inflexible semantics for cross-categorial operators. Cambridge, Massachusetts: MIT dissertation. http://hdl.handle.net/1721.1/113782.

Horn, Laurence. 1981. A pragmatic approach to certain ambiguities. Linguistics and Philosophy 4(3). 321-358. http://www.jstor.org/stable/25001059.

Karttunen, Lauri. 1977. Syntax and semantics of questions. Linguistics and Philosophy 1(1). 3-44. http://www.jstor.org/stable/25000027.

Kotek, Hadas. 2016. Movement and alternatives don't mix: A new look at whintervention effects. Talk given at the 47th annual meeting of the North East Linguistic Society (NELS 47), University of Massachusetts, Amherst, 14-16 October.

Kratzer, Angelika. 1998. Scope or pseudoscope? Are there wide-scope indefinites? In Susan Rothstein (ed.), Events and Grammar, 163-196. Dordrecht: Springer.

Merchant, Jason. 2008. Variable island repair under ellipsis. In Kyle Johnson (ed.), Topics in Ellipsis, 132-153. Cambridge: Cambridge University Press.

Moulton, Keir. 2009. Natural selection and the syntax of clausal complementation. Amherst, Massachusetts: University of Massachusetts Amherst dissertation. https://scholarworks.umass.edu/open_access_dissertations/99.

Roberts, Craige. 1996. Information structure in discourse: Towards an integrated formal theory of pragmatics. In Jae-Hak Yoon \& Andreas Kathol (eds.), Papers in semantics, vol. 49 Ohio State University Working Papers in Linguistics, Department of Linguistics, The Ohio State University.

Rooth, Mats. 1992a. A theory of focus interpretation. Natural Language Semantics 1. 75-116. http://www.jstor.org/stable/23748778.

Rooth, Mats. 1992b. Ellipsis redundancy and reduction redundancy. In Berman \& Hestvik (eds.), The Stuttgart Ellipsis Workshop, SFB 340.

Ross, John R. 1967. Constraints on variables in syntax. Cambridge, Massachusetts: MIT dissertation. http://hdl.handle.net/1721.1/15166.

Russell, Bertrand. 1905. On denoting. Mind 14(4). 479-493. doi:10.1093/mind/XIV.4.479. 
Ellipsis in tautologous conditionals

Stockwell, Richard. 2017. VP ellipsis with symmetrical predicates. In Andrew Lamont \& Katerina Tetzlof (eds.), Forty-seventh annual meeting of the North East Linguistic Society (NELS 47), volume 3, 141-154. GLSA.

Takahashi, Shoichi \& Danny Fox. 2005. MaxElide and the re-binding problem. In Efthymia Georgala \& Jonathan Howell (eds.), Semantics and Linguistic Theory 15 (SALT 15), 223-240. doi:10.3765/salt.v15i0.3095.

Tancredi, Christopher. 1992. Deletion, deaccenting and presupposition. Cambridge, Massachusetts: MIT dissertation. http://hdl.handle.net/1721.1/12893.

Richard Stockwell

3125 Campbell Hall

UCLA

Los Angeles, CA 90095

rstockwell15@ucla.edu 